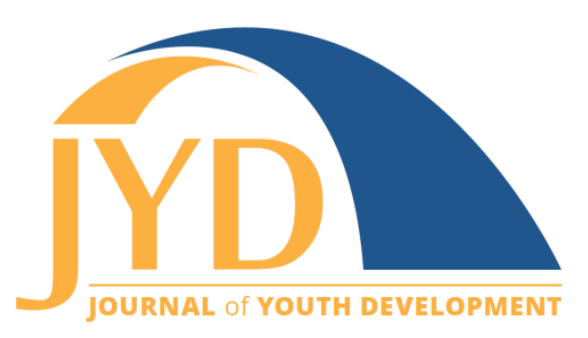

http://jyd. pitt. edu/ | Vol. 14 Issue 2 DOI 10.5195/jyd.2019.685 | ISSN 2325-4017 (online)

\title{
Barriers and Supports to College Aspiration Among Latinx High School Students
}

\author{
Harold Manzano-Sanchez \\ Universidad del Valle, Institute of Education and Pedagogy \\ haroldmanzano@gmail.com \\ David Matarrita-Cascante \\ Texas A\&M University, Department of Recreation, Park and Tourism Sciences \\ dmatarrita@tamu.edu

\section{Corliss Outley} \\ Texas A\&M University, Department of Recreation, Park and Tourism Sciences \\ coutley@tamu.edu
}

\begin{abstract}
This study used a qualitative methodology to identify and describe barriers that Latinx high school students face in their college aspirations and the supports they recognize as pivotal to achieving their goal of attending college. In order to understand barriers and supports for college attendance, 23 Latinx high school students in Southern California participated in 4 focus groups. Students were asked about barriers that most affect the students' college aspirations and varying supports needed to assist in their goal to go to college. The most common barriers reported by them were: lack of financial resources, family responsibilities, lack of teachers' support, peer pressure, and systematic discrimination. The most valuable resources mentioned were: support from their parents, siblings, relatives and teachers. Additionally, support from Latino extended families were vital as they provided encouragement, advice, economic support, and a sense of pride concerning students' achievements. The implications of these findings for social cognitive career theory, practice, policy, and future research are discussed in the paper.
\end{abstract}

Key words: Latinx high school students, college aspirations, barriers, supports, college readiness

(c) $\mathbf{E Y}$ New articles in this journal are licensed under a Creative Commons Attribution 4.0 License. This journal is published by the University Library System, University of Pittsburgh and is cosponsored by the University of Pittsburgh Press. The Journal of Youth Development is the official peer-reviewed publication of the National Association of Extension 4-H Agents and the National AfterSchool Association. 


\section{Introduction}

Latinx high school students in the United States have high postsecondary aspirations (Flores, Navarro, \& DeWitz, 2008; McWhirter, Luginbuhl, \& Brown, 2014; McWhirter, Ramos, \& Medina, 2013); however, in recent years, an average of only $39 \%$ of Latinx high school graduates enroll in college (de Brey et al., 2019). Although overall undergraduate enrollment doubled between 2000 and 2016, Latinx students continue to fall behind their Asian (58\%) and White (42\%) counterparts (de Brey et al., 2019; Sáenz \& Ponjuan, 2012). Among the reasons for the documented lag are the facts that many Latinx are enrolled at high poverty schools $(38 \%)$, attend schools that did not meet adequate yearly progress (AYP) (48\%), and only $38 \%$ of Latinx students attend schools in which the counseling programs prepared them for postsecondary education (Manzano-Sanchez, Outley, Gonzalez, \& Matarrita-Cascante, 2018; Ross et al., 2012). Additional contextual and personal factors include the lack of financial support, reduced school support, limited safety in their neighborhoods, family problems and little knowledge of postsecondary options as barriers that contribute to the gap between Latinx aspirations and college enrollment or higher educational attainment (Bohon, Macpherson, \& Atiles, 2005; Gushue, 2006; McWhirter, Valdez, \& Caban, 2013; Nora, \& Crisp, 2012; Sáenz \& Ponjuan, 2012; Vega, Moore III, \& Miranda, 2015).

Given the dismal numbers presented, it is important to understand the process that Latinx students undergo while also exploring the contextual and personal factors that influence their college aspiration and choice. A better picture of the influence of the environment may consider not only factors that constrain but also those that can facilitate educational aspirations (Lent, Brown, \& Hackett, 2000; Lent, et al., 2002). Identifying and understanding these factors are critical in order to provide support and create just policies that will foster successful career trajectories by closing the gap-not only for Latinx students, but for all students of color.

Social Cognitive Career theory (SCCT) provides a theoretical framework for the current study in that it posits that contextual background variables exert influence over career choice and thus higher educational attainment and its relationship to career trajectories. These variables are determined by (a) personal factors (e.g., gender, ethnicity); (b) background contextual factors (e.g., social support, environment); and (c) proximal contextual variables (e.g., perceived barriers (Lent, et al., 2000). Contextual variables are viewed as supports and barriers that enable or constrain the aspirations of young people during their career development, particularly their family background. SCCT suggests "support and barrier perceptions are inversely related or reflect opposite poles on a positive-negative continuum" (Lent, et al., 2000, 


\section{Barriers and Supports to Latinx Education Goals}

p. 42). In this vein, McWhirter, Valdez, \& Caban (2013) found in Latina high school students, that family may provide both supports (encouragement, understanding, motivation) and barriers (lack of parental support, family problems). In a similar way, teachers provided active engagement, caring expectations, understanding and acceptance as well as negative attitudes toward educational attainment among Latinx students (McWhirter, Valdez, \& Caban, 2013). In career development research, the role of support systems has received less study than barriers. Therefore, SCCT advocates for more research that examines the relationship between perceived supports and barriers toward college aspirations (Lent et al., 2000).

\section{Barriers in the Path of Going to College}

Barriers are events, conditions or negative influences-either within the person or in the environment-which make career development difficult (Lent et al., 2000; Swanson \& Woitke, 1997). Students can identify barriers in past experiences and barriers that hamper present experiences, and anticipate them in the future (Lent et al., 2000).

McWhirter et al. (2007) identified four external and two internal perceived barriers to postsecondary educational plans in a study of Mexican American and White high school students. External barriers were financial, relational, demographic, and separation; internal barriers were ability and preparation/motivation. McWhirter, Valdez, \& Caban (2013), in a qualitative research study identified six types of barriers that Latina adolescents face in their career and educational aspirations. Those themes were: lack of resources, negative peers and peer influence, school-based barriers, family barriers, individual factors, and macrosystemic and exosystemic barriers. Family background characteristics such as low income, immigrant status, parents' educational attainment (Acevedo \& Morales, 2001), and language create an initial barrier in the students' academic achievement that is hard to overcome (Schneider, Martinez, \& Owens, 2006). In addition, Schneider et al. (2006) point out that the most troubling barriers that Latino students face on the road to higher education are insufficient financial resources and inadequate career guidance. In the same way, Latinx students are the least likely to take college entrance examinations and apply to college (Fry, 2004, as cited in Schneider et al., 2006). The barriers mentioned above explain partially why Hispanic students have the lowest rates of college attendance (Sáenz \& Ponjuan, 2012); however, more qualitative research is needed to identify the impact of barriers to Latinx students and college attendance (Nora \& Crisp, 2012; Sáenz \& Ponjuan, 2012). 
Barriers and Supports to Latinx Education Goals

\section{Social Supports in the Path of Going to College}

Supports or support systems are "environmental variables that can facilitate the formation and pursuit of individuals' career choices" (Lent et al., 2000, p. 42). Students under supportive environmental conditions are more likely to pursue their academic interests than students under restrictive environmental conditions (Brown, \& Lent, 2006).

McWhirter, Valdez, \& Caban (2013) conducted a qualitative study to examine the types of supports that Latina high school students perceived of family, teachers and friends. The findings of this research showed that Latina high school students described the most suitable support from their family as the provision of encouragement and understanding, economic support and providing advice, and high career expectations. The most helpful supports from their teachers were related to active engagement, caring expectations, understanding, and acceptance. Concerning friends, the most important supports were understanding and encouragement, assistance with homework and discouragement from engaging in risky behaviors.

Clark, Ponjuan, Orrock, Wilson, \& Flores (2013) identified five types of supports that Latino male students need in their goals of pursuing a higher education: parental support to decrease the pressure to contribute financially to their families, adult mentors as role models, cultural supports groups, financial aid opportunities, and assistance with life transitions from high school to college. In the same vein, Sáenz \& Ponjuan (2011) identified four areas in which schools and postsecondary institutions must develop policies and practices to support college readiness and success of Latino males: family and community engagement; college and career-ready curriculum; linked academic and social supports; and affordability, transparency, and financial literacy. Research in supportive conditions or resources has identified different kinds of supports that Latinx students need for career and academic outcomes; however, less attention has been paid to supports aligned to students' expectations for college success (Sáenz \& Ponjuan, 2011).

\section{Study Purpose}

Latinx youth are the fastest growing population in the United States (Colby \& Ortman, 2015). Although they have high expectations to enter into higher education, their college enrollment rate is still lower than other race/ethnic groups. In the last decades, in order to understand the gap between college aspirations and college enrollment, the interest in examining barriers that hinder and supports that foster the success of Latinx students in higher education has been growing. However, literature is not clear about how Latinx students cope with these barriers 


\section{Barriers and Supports to Latinx Education Goals}

and how they take advantage of the available support in their community. Our study was tasked with finding a deeper understanding of what Latinx students perceive as both barriers and supports in their college aspirations as well as how they overcome these barriers and how they deal with the lack of support. If college readiness programs have a better understanding of both these factors, they will be better able to provide suitable resources, services, and counseling to students and thus increase the enrollment of Latinx students in postsecondary education.

When Latinx high school students are unable to discern a career trajectory, there are both social capital and economic capital losses, which have grave consequences not only for Latinx families but also for U.S. society in general. In this sense, this study makes visible how Latinx high school students deal with socio-institutional and structural barriers to their aspirations of going to college. Sáenz and Ponjuan (2012) suggest conducting qualitative research to better understand the educational experience and outcomes of Latinx, especially in the transition from high school to college. With this in mind, we used a focus groups procedure to (a) provide a more naturalistic environment to collect qualitative data from high school students; (b) stimulate dialogues among students that enable them to compare their own personal reality to that of peers; and (c) obtain students' perceptions, feelings and thinking of barriers and supports to their college aspirations (Krueger \& Casey, 2000).

\section{Method}

\section{Participants}

Participants were 23 Latinx youth between the ages of 15 and 17 enrolled in an urban high school located in Southern California. The high school had an enrollment of 2,346 students, majority Hispanic (92.6\%), and $90.3 \%$ of the student body were socio-economic disadvantaged (SED) students. For this reason, all of the students participating in this study qualified for free or reduced lunch.

\section{Moderators}

Moderators were two doctoral students in Youth Development (a Latino male in his late 40s and an African American female in her late 20s). Both had prior experience working with young people. 


\section{Procedure}

Prior to conducting the focus groups, the students and their parents filled out the minor assent and parent consent forms. Participants were divided into two groups of females (seven and five participants) and two groups of males (six and five participants). Homogeneity and the level of acquaintance were the criteria to divide the groups by gender and to facilitate the discussions (Hennink, 2014). The focus groups were conducted within a 1-week period, and each lasted approximately one hour. The focus groups were conducted in English; they were audiorecorded and notes were taken in each of the groups. Two focus groups were conducted on each of 2 days; moderators debriefed at the end of each day. These open discussions between moderators provided useful feedback on the focus group process (Spall, 1998).

\section{Interview Protocol}

Each focus group session was organized in four sections: introduction, barriers that impede students' college aspirations, supports that foster students' college aspirations, and closing. The interview guide included guiding questions that supported each of the four sections (e.g., Barriers section: What are the barriers that most affect students' college aspirations? Support section: What types of supports do you think high school students need to achieve their goal of going to college, and why?) Moderators allowed participants to spend more time on questions and topics that generated greater participation; however, some discussions were shortened because of time constraints.

\section{Data Analysis}

Focus group recordings were transcribed by three undergraduate students and by the first author. Some portions of the recordings were inaudible due to speakers speaking in low voices or speaking simultaneously, or due to background noise, so those phrases were not transcribed. After transcripts were verified, the data were analyzed following three interwoven steps: (a) data reduction: data are sharpened, focused, discarded, and organized; (b) data display: the assembly of the organized information into graphs, charts, maps, and matrices for easier interpretation; (c) drawing conclusions and verification: attributing the meaning that emerges, and then reviewing the data and conclusions a second time (Miles \& Huberman, 1994). 


\section{Coding}

Coding began before any data were collected because the two central themes (barriers and supports) and their categories were identified in the preliminary outline. However, during the reading of the transcription, new categories emerged and enriched the preliminary outline (Miles \& Huberman, 1994).

One researcher read all responses to the given questions across the four focus groups and then assigned each idea or statement to a particular category of a particular theme. All statements were associated with the participant and the group respectively (e.g., "Aaron M1" indicates Aaron, a male in group 1; "Maggie F2" indicates Maggie, a female in group 2). Each statement was placed in a category of a particular theme and then all statements were counted for each theme. Next, a second researcher and a doctoral student reviewed the outline, the transcripts, and coding; raised questions; and made recommendations for coding decisions. Discrepancies were resolved by consensus. This process of triangulation was used to increase the trustworthiness (reliability, credibility, confirmability, and validity) of the outline, analysis, and coding processes (Miles \& Huberman, 1994). 


\section{Results}

Table 1 summarizes the barriers and supports students identified to their aspirations to going to college.

Table 1. Themes, Categories, and Descriptions of Personal and Contextual Factors

\begin{tabular}{|c|c|c|}
\hline Theme & Category & Description \\
\hline Barriers & $\begin{array}{l}\text { - } \text { Not enough money } \\
\text { - } \text { Family responsibilities } \\
\text { - } \text { Having a job or working outside of school } \\
\text { - } \quad \text { Not being prepared enough } \\
\text { - } \quad \text { Not enough confidence } \\
\text { - } \quad \text { Not enough help with figuring out the steps } \\
\text { - } \text { of going to college } \\
\text { - } \quad \text { Lack of teacher and counselor support }\end{array}$ & $\begin{array}{l}\text { Financial, demographic, } \\
\text { relational, preparation, } \\
\text { motivation, and ability barriers } \\
\text { that students face in their } \\
\text { college aspirations }\end{array}$ \\
\hline Supports & $\begin{array}{l}\text { - } \text { Family members } \\
\text { - } \text { Friends or relatives } \\
\text { - } \text { Other important people } \\
\text { - Counselors, teachers, school }\end{array}$ & $\begin{array}{l}\text { Support from parents, relatives, } \\
\text { teachers, counselors, and } \\
\text { important people that students } \\
\text { need in the path of going to } \\
\text { college }\end{array}$ \\
\hline
\end{tabular}

The students provided insightful explanations of barriers that affect students' college aspirations as well as supports they need on the road to go to college.

\section{Barriers}

\section{Not Enough Money}

The lack of family financial resources was perceived as the biggest barrier to going to college for these students. For example, one student stated, "If we realize that we don't even have enough money to pay even our rent then, where are we going to have money to pay for our college?" (Aundrea F2). The lack of financial resources is further exacerbated when the students are viewed as one of the primary supporters for their families. Financial aid was one option to help the students with college expenses, but participants provided arguments about 


\section{Barriers and Supports to Latinx Education Goals}

the difficulties to access scholarships and the advantages and disadvantages of getting a student loan. Few students stated that the lack of economic support is not a barrier to going to college.

\section{Family Responsibilities}

Family responsibilities resonated strongly with the participants as barriers to going to college. As family members, students have to contribute to regular or unexpected family expenses. "They need to get a job to help their parents, like . . . pay for the rent since they're still going to be living at home ... or to help their parents with other stuff." (Bella F1). Several participants agreed that older siblings have more family responsibilities than younger siblings. According to participants, family responsibilities are assigned according to gender: females are responsible for household chores and males for economic support. The participants also discussed that some students take on adult responsibilities because their parents are unable to take care of their families due to parents having a severe illness or being irresponsible.

\section{Having a Job or Working Outside of School}

Participants stated that jobs interfere with the goal of going to or remaining in college due to increased work responsibilities or economic obligations that force students to drop out of college. "They aren't able to advance [higher education] because they have to worry about their job and pay the bill and all that" (Jesus M2). Students stated that time management is a skill that people need to develop to alternate both activities at the same time. In addition, other participants identified working and studying at the same time as difficult, requiring students to be skillful in managing their time.

\section{Lack of Opportunities}

Lack of opportunities came up as a barrier only in the discussions with males. "Probably 'cuz there's too much competition in the field they want to enter and they just probably feel they're not fit to it. And just like quit afterward" (Ricky M1). Another participant remarked that females have more opportunities than males to go to college because there are programs that encourage women to go to college, especially in STEM fields such as engineering. 


\section{Not Being Prepared Enough}

Students provided several examples of how they felt high school did not prepare them for academic success. "A lot of people don't know how to get some basic skills in school, like, taking notes because if you don't know, then, you will start to fail classes" (Jesus M2). Another student described her lack of preparation in math and how this situation makes her feel insecure to take college exams.

\section{Not Enough confidence}

Low academic confidence caused by a lack of previous experiences of high academic success would serve as a barrier to college. "You're thinking that [college is] harder than [high school] and then people put themselves down, thinking that they can't do it" (Jeffrey M2). Negative feedback was also mentioned as contributing to low confidence: ". . . having anyone telling me: 'Oh, you're not good at what you do'"' (Alex F2). Low academic performance is another perceived barrier; students with low grades feel defeated in their college aspirations. Academic competition with peers also decreases their self-confidence.

\section{Not Enough Help in Figuring out the Steps of Going to College}

One participant mentioned that male students do not feel comfortable asking for help. "Guys are too afraid to ask for that help. ... So, they try to avoid asking for help which in that case, it's just, gonna bring you down" (Jack M2). Another student perceived that they did not receive the help they need. Conversely, another student considered that students have different types of resources to obtain information about the steps they need to follow to go to college.

\section{Peer Pressure}

Participants recognized pressure from students who do not value going to college as a barrier. One participant expressed that there were peers that force students to do activities that they did not feel comfortable doing. "He's gonna have to be forced into doing something he really doesn't want to do" (James M1).

\section{Lack of Support From Teachers and Counselors}

This lack of support in assisting with the students' learning processes was perceived as a barrier to going to college. "There're some teachers that don't really teach you because they really don't care about your education" (Bella F1). One student recognized that teachers give support 


\section{Barriers and Supports to Latinx Education Goals}

to students with low academic performance, but only when failure is imminent. Although students recognized that teachers and counselors offer help during the school schedule, the students feel uncomfortable asking them for help.

\section{Supports}

\section{Family Members' Support}

Parents and siblings were the most valuable support that students have in their goal to go to college. Several students claimed that family is a source of advice and inspiration: "My whole family is my biggest inspiration" (Julius M2). Parents wanting a better life for their children was a consistent idea. Parents motivate and push their children to reach academic goals, and parents express to their children that they will be proud if their children are successful. The difficulties that parents face in their unskilled jobs were also factors that motivate the students to go to college.

\section{Friends and Relatives' Support}

Participants stated that they received support from their friends and peers and that they were willing to help and support their friends to achieve academic goals as well. "You want to encourage your best friend because you want to see him go to college" (Aaron M1). Friends are also a source of support when students do not have support at home.

\section{Other Important People's Support}

Relatives encouraged the students to achieve academic goals. One student considered national leaders such as César Chavez and Martin Luther King, Jr. as a source of inspiration. Another student described people who are like the participants or have overcome difficulties like they have to be a source of inspiration.

\section{Support from Counselors, Teachers, and School}

Students recognized the value of counseling at school as pivotal in their college aspirations, "Counselors would be . . . the most important because . . . they know more about college than probably your family members and friends." (J. Cole M2). Students perceived teachers with characteristics similar to them as supports to going to college. For instance, teachers who live in the same neighborhood or have overcome barriers to go to college might provide a suitable 


\section{Barriers and Supports to Latinx Education Goals}

support to the students because they can understand the challenges that students face in their everyday lives.

\section{Overcome Barriers}

Students with low confidence are unable to overcome barriers. "My confidence is really low. So, it's just ... trying to get the fact ... it's hard to do something knowing that you're going to fail." (Jack M2). Many students felt that an appropriate way to overcome difficulties was to get reliable information. Another way was finding alternative options in higher education that is different from attending a 4-year College. Likewise, one student remarked there are different kinds of help that student can get to overcome barriers. "You can get help at home or . . . there are a lot of places that offer help like, at school there's SAT camp that helps" (Julius M2).

\section{Succeed Without Support}

Students have a firm conviction that they can succeed without support, the only thing they need is an inner desire. "Just with the right motivation, you could be able to go to college, even if you don't have ... s support from everyone else." (Estella F2). Students also described experiences of acquaintances that have succeeded without support. In addition, one student identified how vicarious experiences could contribute to increasing coping self-efficacy: "Talk to someone that has taken the SAT or also is writing the essay and get advice from them" (Matthew M1). Nonetheless, the lack of economic support hinders their college aspirations: "With no support, it would be hard to do something. I mean, you could still do it; but is harder and financial pressure." (Maggie F2). The lack of support also decreases the students' coping self-efficacy. "They're demoralized because they see other people getting support and then, they have nothing. So, they don't think they're going to make it." (James M1).

\section{Discussion}

\section{Barriers to Overcome}

Latinx high school students in our study experienced more barriers that hinder their college aspirations than supports that facilitated them. The lack of financial resources was viewed as the primary barrier that is difficult to overcome. This finding is consistent with previous studies in which the lack of financial resources is a barrier to college aspirations for Latinx students (McWhirter et al., 2007; McWhirter, Valdez, \& Caban, 2013). Latinx students do not perceive scholarships and student loans as appropriate financial assistance for college. These students 


\section{Barriers and Supports to Latinx Education Goals}

do not know where to look and how to apply for scholarships, or they often feel they do not meet the necessary requirements to earn them.

The second barrier to college aspirations difficult to overcome was family responsibilities. Our study found that high levels of family responsibilities become a difficult barrier to overcome for Latinx high school students who assume the roles of providers, protectors, and caregivers of younger siblings. These adult roles interfere with the participation in pro-college activities. This finding is similar to those of Lopez (2009), who found that the principal reason Latinx youth were not enrolled in high school or higher education was the need to support their family.

Latino males brought up two viewpoints on the barrier of lacking access to opportunities: there are highly competitive majors in which they do not fit, and there are more college access programs for females than for males. These perceptions discourage them from accessing higher education. When the negative stereotype is activated, Latinos tend to underperform particularly on cognitive and aptitude tests (Schneider et al., 2006).

Latinx high school students feel they are not prepared enough to go to college and therefore their level of confidence in this pursuit is low. This lack of preparation is perceived as a challenging barrier. Latinx students in our study perceived different reasons for this lack of preparedness: they are taking courses with low levels of thoroughness, they receive negative feedback from their teachers, and few teachers go out of their way to help to prepare students for SAT's and the college essays. Literature about college access shows that students in lowincome schools are less likely to complete a rigorous curriculum and receive the one-on-one help that would prepare them for college admission than students in middle- and high-income schools (Tierney, Constantine, Finkelstein, \& Hurd, 2009). Another factor that undermines the confidence in Latinx high school students is an atmosphere that sends a message of inferiority and discrimination based on their phenotype or ethnic identity (Manzano-Sanchez et al., 2018; Noguera, 2001; Padilla, 2006). This structural stigmatization maintains and reinforces the barriers and makes it difficult for Latinx students to access resources that would improve their college preparation.

We found that peer pressure from youth that do not value college aspirations is perceived as a challenging barrier that sometimes results in students behaving improperly. Similarly, Castillo, Conoley, Cepeda, Ivy, \& Archuleta (2010) found that peers could tempt students into troublesome situations, and they were not a suitable support system to talk about grades, career aspirations and college life. 
Similarly, the lack of teachers' support is perceived as a challenging barrier for Latinx students in our study. Prior studies found that some teachers lacked sufficient empathy regarding the cultural context of Latinx students (Valenzuela, 2010), and teachers' lack of positive interaction contributes to decreased students' academic performance (Schneider et al., 2006).

Latinx students did not perceive work as a significant barrier to their college aspirations. Many students see getting a job as the only option for obtaining the financial resources necessary for college expenses. This finding is somewhat similar to the results of a study that found a positive relationship between work and study at the same time in college students who work 20 hours or less a week (Pike, Kuh, \& Massa-McKinley, 2008). However, Latinx students remarked that they did not know how to manage both activities at the same time. This finding suggests that Latinx students need guidelines to manage their time more efficiently and balance study and work activities.

\section{Significant Adults as Pivotal Support}

Findings of this study suggest that encouragement, advice, and help from parents, siblings, and relatives were the most valuable supports for Latinx high school students and they are able to take advantages of these kinds of support. In this vein, parents provided emotional and financial support, and relatives with college experience provided emotional and informational support. These findings are consistent with previous studies in which parents provide parental support in academic pursuits, career decision and college entry (Castillo et al., 2010; Ceja, 2004; Graff, McCain, \& Gomez-Vilchis, 2013; McWhirter et al., 2007; Metheny \& McWhirter, 2013). This finding is also consistent with studies of parents' support in which their lack of higher education is a source of motivation for their children to surpass them in educational attainment (Ceja, 2004; Metheny \& McWhirter, 2013; Sánchez, Reyes, \& Singh, 2006).

One remarkable finding of this study is that friends and close peers provide emotional, informational, and appraisal support mutually. In this vein, Latinx students surrounded by other peers interested in higher education tend to share goals, academic and extracurricular activities associated with successful college entry (Brown \& Lent, 2006; Pérez \& McDonough, 2008; Turner \& Lapan, 2005). 


\section{Barriers and Supports to Latinx Education Goals}

Participants in the focus groups recognized the fundamental role their counselors play in providing reliable information for college access; however, counselors' availability is not enough to cover the students' initial interests in college preparation.

Understandably, overcoming these barriers is a challenging task, particularly for students who are surrounded by unhealthy environments and have low self-efficacy beliefs (Brown \& Lent, 2006); many of the participants in the focus groups might fall into this category. However, students provided several strategies to cope with those barriers: problem-solving (i.e., take SAT preparation programs, apply for scholarships); information seeking (i.e., get reliable information about college steps); self-reliance (to make up their own mind, assert self-motivation and personal effort); support-seeking (i.e., talk to friends and tutors with college experience, counselors); and negotiation (find alternative paths in career development different from college or find a part-time job to pay college expenses) (Skinner \& Zimmer-Gembeck, 2007).

\section{Recommendations for Policy and Practice}

\section{Help Parents to Balance Family Responsibilities With College Preparation}

Parents need some guidance to learn how to balance the students' family responsibilities and college preparation. Counselors and teachers might facilitate meetings in which parents discuss and share views of Latino family culture (i.e., family duties, values, heritage, gender roles, and financial budget), and facilitators discuss and share themes of college readiness (college examinations, steps to apply to college, criteria to select a career, financial aid resources, and college budget).

\section{Foster Caring Relationships Between Teachers And Students}

Teachers are valued when they establish caring relationships, push the students to raise their academic performance, and respect Latino heritage. Teachers who build caring relationships not only impact the development of social skills but also contribute to raising the Latinx students' academic interest. In a similar way, Latinx students value teachers that challenge them to increase their academic performance and teachers who avoid expressions that reinforce negative stereotypes. 


\section{Barriers and Supports to Latinx Education Goals}

\section{Stimulate a College-Going Culture}

School districts can find guidelines to establish the foundation of a college-going culture from elementary to high school. Some organizations have developed guides to help school districts develop policies, programs, and actions aimed at Latinx students making a smooth transition from high school to college. The establishment of community partnerships is a suitable way to coordinate and mobilize public and private resources, reduce competition among organizations, and decrease the duplication of services (Outley, Bocarro, \& Boleman, 2011).

\section{Offer a Rigorous Curriculum That Prepares Students for College-Level Work}

Offering rigorous courses and a curriculum that prepares students for the demands of higher education is crucial in a college-going culture (Tierney et al., 2009). The role of the school administrators is not only to provide access to these courses, but also to ensure that Latinx students understand the importance of following a college-ready curriculum (Tierney et al., 2009).

\section{Assess the Student Process in the Path of Going to College}

In addition to regular evaluations of the courses, high schools should implement collegereadiness assessments that allow them to identify Latinx students' strengths and weakness in knowledge and skills needed to succeed in college.

\section{Provide Differentiated Support for Female and Male Students}

Latina and Latino high school students need different types of support on the road to college. This study found that both genders perceived a lack of preparation; however, Latinas were more able to ask for help than their Latino counterparts.

\section{Conclusions}

Latinx high school students in our study experienced more barriers that were difficult to overcome and hindered their college aspirations than supports that facilitated them. The most pivotal barriers that Latinx high school students face are the following:

1. Lack of family financial resources and limited knowledge of financial aid opportunities. 


\section{Barriers and Supports to Latinx Education Goals}

2. Family responsibilities that affect students' academic performance: Sons assume the roles of providers and protector; daughters take on the roles of caregivers of younger siblings and homemakers of household chores.

3. Teachers who did not provide adequate levels of academic support to help to prepare the students for college exams or did not put in enough effort to establish the type of teacher-student relationships in which students feel comfortable in asking for help. In addition, there are some teachers who were not sensitive to Latino culture and did not understand that Latino culture values caring relationships in teaching-learning processes (Castillo et al., 2010; Ogbu \& Simons, 1998; Valenzuela, 2010).

4. Negative peer pressure that discourages students from pursuing higher education and, in some cases, peer influence on students to behave improperly.

The results also suggest that the most valuable resources that Latinx students have in their college aspirations are the following:

1. Support from their parents, siblings, and relatives. Latino families provide encouragement, advice, economic support, and a sense of pride concerning the students' achievements. Although parents cannot offer suitable information pertaining to the college process, they offer their experiences with hardship that push their children to overcome difficulties and improve family conditions.

2. Counselors and teachers have reliable information and resources to develop the knowledge and skills that students require to navigate their college journey.

3. Friendship was a significant support. When Latinx students are surrounded by friends with similar academic goals, they can overcome barriers that stand in the path to college.

The most valuable conclusion of this study is that Latinx high school students are aware of their constraints and are capable of determining ways to overcome them. However, they need responsible adults-parents, counselors and teachers-to challenge them to develop the knowledge, skills, and values required to succeed academically. Likewise, if they expect to embark on a particular path in their career development, Latinx high school students need guidance to establish realistic goals according to their capabilities and desired outcomes (Lent \& Brow, 2006). 


\section{References}

Acevedo, G., \& Morales, J. (2001). Assessment with Latino/Hispanic communities and organizations. In R. Fong \& S. B. Furuto (Eds.), Cultural competent practice skills, interventions, and evaluations (pp. 147-162). Needham Heights, MA: Pearson Education.

Bohon, S. A., Macpherson, H., \& Atiles, J. H. (2005). Educational barriers for new Latinos in Georgia. Journal of Latinos and Education, 4(1), 43-58. doi:10.1207/s1532771xjle0401_4

Brown S. D., \& Lent, R. W., (2006). Preparing adolescents to make career decisions. A social cognitive perspective. In F. Pajares and T. Urdan (Eds.), Self-efficacy beliefs of adolescents (pp. 201-223). Greenwich, CT: Information Age Publishing.

Castillo, L. G., Conoley, C. W., Cepeda, L. M., Ivy, K. K., \& Archuleta, D. J. (2010). Mexican American adolescents' perceptions of a pro-college culture. Journal of Hispanic Higher Education, 9(1), 6172. doi:10.1177/1538192709350454

Ceja, M. (2004). Chicana college aspirations and the role of parents: Developing educational resiliency. Journal of Hispanic Higher Education, 3, 338-362. doi:10.1177/1538192704268428

Clark, M. A., Ponjuan, L., Orrock, J., Wilson, T., \& Flores, G. (2013). Support and barriers for Latino male students' educational pursuits: Perceptions of counselors and administrators. Journal of Counseling \& Development, 91(4), 458-466. doi:10.1002/j.1556-6676.2013.00118.x

Colby, S. L., \& Ortman, J. M. (2015). Projections of the size and composition of the US population: 2014 to 2060 (U.S. Census Bureau, Ed, 25-1143). Retrieved from https://www.census.gov/content/dam/Census/library/publications/2015/demo/p25 -1143.pdf

de Brey, C., Musu, L., McFarland, J., Wilkinson-Flicker, S., Diliberti, M., Zhang, A., . . Wang, X. (2019). Status and trends in the education of racial and ethnic groups 2018 (NCES 2019-038). U.S. Department of Education. Washington, DC: National Center for Education Statistics. Retrieved from https://nces.ed.gov/pubs2019/2019038.pdf

Flores, L. Y., Navarro, R. L., \& DeWitz, S. J. (2008). Mexican American high school students' postsecondary educational goals: Applying social cognitive career theory. Journal of Career Assessment, 16(4), 489-501. doi:10.1177/1069072708318905

Fry, R., \& Taylor, P. (2013). Hispanic high school graduates pass Whites in rate of college enrollment. Retrieved from Pew Research Center website: https://www.pewresearch.org/wpcontent/uploads/sites/5/2013/05/PHC_college_enrollment_2013-05.pdf

Graff, C. S., McCain, T., \& Gomez-Vilchis, V. (2013). Latina resilience in higher education: Contributing factors including seasonal farmworker experiences. Journal of Hispanic Higher Education, 12(4), 334-344. doi:10.1177/1538192713494212 


\section{Barriers and Supports to Latinx Education Goals}

Gushue, G. V. (2006). The relationship of ethnic identity, career decision-making self-efficacy and outcome expectations among Latino/a high school students. Journal of Vocational Behavior, 68(1), 85-95. doi:10.1016/j.jvb.2005.03.002

Hanson, S. L. (1994). Lost talent: Unrealized educational aspirations and expectations among U.S. youths. Sociology of Education, 67, 159-183.

Hennink, M. M. (2014). Focus group discussions: Understanding qualitative research. New York, NY: Oxford University Press.

Krueger, R. A., \& Casey, M. A. (2000). Focus groups: A practical guide for applied research (3 $3^{\text {rd }}$ ed.). Thousand Oaks, CA: Sage.

Lent, R. W., Brown, S. D., \& Hackett, G. (2000). Contextual supports and barriers to career choice: A social cognitive analysis. Journal of Counseling Psychology, 47(1), 36. doi:10.1037/00220167.47.1.36

Lent, R. W., Brown, S. D., Talleyrand, R., McPartland, E. B., Davis, T., Chopra, S. B., . . Chai, C. M. (2002). Career choice barriers, supports, and coping strategies: College students' experiences. Journal of Vocational Behavior, 60(1), 61-72. doi:10.1006/jvbe.2001.1814

Lopez, M. H. (2009). Latinos and education: Explaining the attainment gap. Retrieved from Pew Research Center website: https://www.pewresearch.org/wp-content/uploads/sites/5/reports/115.pdf

Manzano-Sanchez, H., Outley, C., Gonzalez, J. E., \& Matarrita-Cascante, D. (2018). The influence of selfefficacy beliefs in the academic performance of Latina/o students in the United States: A systematic literature review. Hispanic Journal of Behavioral Sciences, 40(2), 176-209. doi:10.1177/0739986318761323

McWhirter, E. H., Luginbuhl, P. J., \& Brown, K. (2014). iApóyenos! Latina/o student recommendations for high school supports. Journal of Career Development, 41(1), 3-23.

McWhirter, E. H., Ramos, K., \& Medina, C. (2013). ¿Y ahora qué? Anticipated immigration status barriers and Latina/o high school students' future expectations. Cultural Diversity and Ethnic Minority Psychology, 19(3), 288. doi:10.1037/a0031814

McWhirter, E. H., Valdez, M., \& Caban, A. R. (2013). Latina adolescents' plans, barriers, and supports: A focus group study. Journal of Latina/o Psychology, 1(1), 35. doi:10.1037/a0031304

Metheny, J., \& McWhirter, E. H. (2013). Contributions of social status and family support to college students' career decision self-efficacy and outcome expectations. Journal of Career Assessment, 21(3), 378-394. doi:10.1177/1069072712475164

Miles, M. B., \& Huberman, A. M. (1994). Qualitative data analysis: An expanded sourcebook. Thousand Oaks, CA: Sage.

Noguera, P. A. (2001). Transforming urban schools through investments in the social capital of parents. Psychology, 16, 725-50 


\section{Barriers and Supports to Latinx Education Goals}

Nora, A., \& Crisp, G. (2012). Future research on Hispanic students: What have we yet to learn? and What new and diverse perspectives are needed to examine Latino success in higher education? White Paper Prepared for the Hispanic Association of Colleges and Universities. Retrieved from https://www.hacu.net/images/hacu/OPAI/H3ERC/2012_papers/Nora\%20crisp\%20\%20future\%20research\%20on\%20hispanics\%20-\%202012.pdf

Ogbu, J. U., \& Simons, H. D. (1998). Voluntary and involuntary minorities: A cultural-ecological theory of school performance with some implications for education. Anthropology \& Education Quarterly, $29(2), 155-188$.

Outley, C., Bocarro, J. N., \& Boleman, C. T. (2011). Recreation as a component of the community youth development system. New directions for youth development, 2011(130), 59-72. doi:10.1002/yd.397

Padilla, A. M. (2006). Bicultural social development. Hispanic Journal of Behavioral Sciences, 28(4), 467497. doi:10.1177/0739986306294255

Pérez, P. A., \& McDonough, P. M. (2008). Understanding Latina and Latino college choice: A social capital and chain migration analysis. Journal of Hispanic Higher Education, 73 , 249-265. doi:10.1177/1538192708317620

Pike, G. R., Kuh, G. D., \& Massa-McKinley, R. C. (2008). First-year students' employment, engagement, and academic achievement: Untangling the relationship between work and grades. Naspa Journal, 45(4), 560-582. doi:10.2202/1949-6605.2011

Sáenz, V. B., \& Ponjuan, L. (2011). Men of color: Ensuring the academic success of Latino males in higher education. Retrieved from Institute for Higher Education Policy website: http://www.ihep.org/sites/default/files/uploads/docs/pubs/brief_men_of_color_latinos.pdf

Sáenz, V. B., \& Ponjuan, L. (2012). Latino males: Improving college access and degree completion: A new national imperative. Perspectivas, Issues in Higher Education Policy and Practice, Spring 2012(1). Retrieved from https://files.eric.ed.gov/fulltext/ED571015.pdf

Sánchez, B., Reyes, O., \& Singh, J. (2006). Makin' It in College: the Value of Significant Individuals in the Lives of Mexican American Adolescents. Journal of Hispanic Higher Education, 5(1), 48-67. doi:10.1177/1538192705282570

Schneider, B., Martinez, S., \& Owens, A. (2006). Barriers to educational opportunities for Hispanics in the United States. In M. Tienda \& F. Mitchell (Eds.), Hispanics and the future of America. Panel of Hispanics in the United States (pp. 179-227). Washington, D.C: The National Academies Press.

Skinner, E. A., \& Zimmer-Gembeck, M. J. (2007). The development of coping. Annual Review of Psychology, 58, 119-144. doi:10.1146/annurev.psych.58.110405.085705

Spall, S. (1998). Peer debriefing in qualitative research: Emerging operational models. Qualitative Inquiry, 4(2), 280-292. doi:10.1177/107780049800400208 


\section{Barriers and Supports to Latinx Education Goals}

Swanson, J. L., \& Woitke, M. B. (1997). Theory into practice in career assessment for women: Assessment and interventions regarding perceived career barriers. Journal of Career Assessment, 5(4), 443-462. doi:10.1177/106907279700500405

Tierney, W. G., Bailey, T., Constantine, J., Finkelstein, N., \& Hurd, N. F. (2009). Helping students navigate the path to college: What high schools can do. National Center for Education Evaluation and Regional Assistance, Institute of Education Sciences, US Department of Education, 2009. Retrieved from https://ies.ed.gov/ncee/wwc/Docs/PracticeGuide/higher_ed_pg_091509.pdf

Turner, S. L., \& Lapan, R. T. (2005). Promoting career development and aspirations in school-age youth. In S. D. Brown \& R. W. Lent (Eds) Career development and counseling: Putting theory and research to work (pp. 417-440). Hoboken, NJ: John Wiley \& Sons.

Valenzuela, A. (2010). Subtractive schooling: US-Mexican youth and the politics of caring. Albany, NY: Suny Press.

Vega, D., Moore J. L., III, \& Miranda, A. H. (2015). In their own words: Perceived barriers to achievement by African American and Latino high school students. American Secondary Education, 43(3), 36.

Zuniga, M. E. (2001). Latinos: Cultural competence and ethics. In R. Fong \& S. B. Furuto (Eds.), Cultural competent practice skills, interventions, and evaluations (pp. 47-60). Needham Heights, MA: Pearson Education. 